University of Nebraska - Lincoln

DigitalCommons@University of Nebraska - Lincoln

Biological Systems Engineering: Papers and

Publications

Biological Systems Engineering

2011

EVALUATION OF A STREAM-AQUIFER ANALYSIS TEST FOR

DERIVING REACH-SCALE STREAMBED CONDUCTANCE

Garey A. Fox

Oklahoma State University - Main Campus, gafox2@ncsu.edu

Derek M. Heeren

University of Nebraska-Lincoln, derek.heeren@unl.edu

Michael A. Kizer

Oklahoma State University - Main Campus

Follow this and additional works at: https://digitalcommons.unl.edu/biosysengfacpub

Part of the Biological Engineering Commons

Fox, Garey A.; Heeren, Derek M.; and Kizer, Michael A., "EVALUATION OF A STREAM-AQUIFER ANALYSIS

TEST FOR DERIVING REACH-SCALE STREAMBED CONDUCTANCE" (2011). Biological Systems

Engineering: Papers and Publications. 220.

https://digitalcommons.unl.edu/biosysengfacpub/220

This Article is brought to you for free and open access by the Biological Systems Engineering at DigitalCommons@University of Nebraska - Lincoln. It has been accepted for inclusion in Biological Systems Engineering: Papers and Publications by an authorized administrator of DigitalCommons@University of Nebraska Lincoln. 


\title{
Evaluation of a Stream-Aquifer Analysis Test for Deriving Reach-Scale Streambed Conductance
}

\author{
G. A. Fox， D. M. Heeren， M. A. Kizer
}

\begin{abstract}
Extracting groundwater from pumping wells located adjacent to streams can reduce streamflow, a result that is known as alluvial well depletion. Numerous analytical solutions have been developed for alluvial well depletion that vary in their mathematical complexity. Predicted drawdown by the analytical solutions can be matched to observed drawdown from a stream-aquifer analysis (SAA) test (i.e., a pumping test adjacent to a stream) to simultaneously estimate aquifer and streambed hydrologic parameters. However, only a few SAA tests have been documented in the literature and compared to field-measured streambed parameters. Therefore, the objective of this research was to perform an SAA test for the purpose of evaluating the ability of analytical solutions, when applied to the SAA test data, to estimate reach-scale streambed conductance. The SAA test was performed at a well site located adjacent to the North Canadian River in central Oklahoma. Observation wells were installed between the stream and the pumping well and were instrumented with automated water level loggers. The pumping well, located approximately $85 \mathrm{~m}$ from the North Canadian River, discharged at a constant rate $\left(2180 \mathrm{~m}^{3} \mathrm{~d}^{-1}\right)$ for $90 \mathrm{~h}$. Predicted drawdown by an analytical solution was fit to the observed drawdown to inversely estimate the transmissivity (790 to $\left.950 \mathrm{~m}^{2} \mathrm{~d}^{-1}\right)$, specific yield (0.19 to 0.28), and streambed conductance (600 to $\left.1500 \mathrm{~m} \mathrm{~d}^{-1}\right)$, which was compared to values derived from in-stream measurements (i.e., grain-size analyses on streambed sediment samples and in-stream falling-head permeameter tests). Estimated streambed conductance from the in-stream measurements and the SAA test were both on the order of $1000 \mathrm{~m} \mathrm{~d}^{-1}$. The similarity in estimates supported the use of SAA tests to derive reach-scale streambed conductance. Both the SAA test and in-stream conductivity measurements suggested minimal streambed hydraulic resistance. Therefore, for this and other streams, simpler analytical solutions may be adequate to inversely estimate the aquifer and streambed hydrologic parameters.
\end{abstract}

Keywords. Alluvial groundwater, Analytical solutions, Groundwater pumping, Stream-aquifer analysis test, Stream depletion.

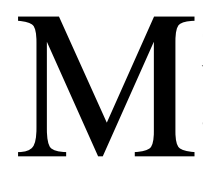
ethodologies using analytical solutions are widely applied in administering tributary groundwater rights (Spalding and Khaleel, 1991). For example, the U.S. Geological Survey standardized a procedure for analyzing the timing of flows between an aquifer and stream, called the stream depletion factor (SDF). Jenkins (1968) originally developed the SDF in studying stream depletion by groundwater pumping. The SDF was defined as the time (d) when the volume of stream depletion reaches $28 \%$ of the total volume pumped. Mathematically, SDF was expressed as:

$$
\mathrm{SDF}=\frac{L^{2} S}{T}
$$

where $L$ is the perpendicular distance from the pumped well to the stream (m), $S$ is the aquifer storage coefficient or

Submitted for review in May 2010 as manuscript number SW 8598; approved for publication by the Soil \& Water Division of ASABE in February 2011.

The authors are Garey A. Fox, ASABE Member Engineer, Associate Professor, Derek M. Heeren, ASABE Member Engineer, Research Engineer and Doctoral Student, and Michael A. Kizer, Emeritus Professor, Department of Biosystems and Agricultural Engineering, Oklahoma State University, Stillwater, Oklahoma. Corresponding author: Garey A. Fox, Department of Biosystems and Agricultural Engineering, Oklahoma State University, 120 Agricultural Hall, Stillwater, OK 74078; phone: 405 744-8423; fax: 405-744-6059; e-mail: garey.fox@okstate.edu. specific yield (depending on the aquifer) and also referred to as storativity, and $T$ is the transmissivity of the aquifer $\left(\mathrm{m}^{2} \mathrm{~d}^{-1}\right)$.

The SDF methodology makes several simplifying assumptions about the flow regime and streambed-aquifer interface and, in general, makes use of the Theis (1941) solution. The Theis (1941) solution assumed an infinitely long, straight, completely penetrating stream in a homogeneous aquifer, as shown in figure 1a. Changes in water table elevations were assumed small compared to the saturated thickness of the aquifer. The ratio of vertical to horizontal velocity components was assumed small, leading to the Dupuit flow assumption. No parameters accounted for a semipervious streambed layer. Applying the principle of superposition, image wells were used to simulate a constanthead boundary at the stream, and drawdown $\left(s_{w}\right)$ in the semiinfinite domain (m) was given by:

$$
\begin{aligned}
& s_{w}(r, t)=\frac{Q}{4 \pi T}\left[E_{1}(u)-E_{1}\left(u_{i}\right)\right] \\
& u=\frac{r^{2} S}{4 T t}, u_{i}=\frac{r_{i}^{2} S}{4 T t}
\end{aligned}
$$

where $r$ and $r_{i}$ are the radial distances between the pumping well or imaginary well and the point of interest (m), $t$ is the time (d), $Q$ is the pumping rate $\left(\mathrm{m}^{3} \mathrm{~d}^{-1}\right), u$ is the Boltzmann variable, and $E_{1}(u)$ and $E_{1}\left(u_{i}\right)$ are the well functions or 
exponential integrals (Charbeneau, 2000) for the real and image well, respectively.

In addressing limitations of the Theis equation, Hantush (1965) developed an analytical model that considered the effects of a semipervious streambed (fig. 1b), a common feature in many alluvial systems (Landon et al., 2001). The semipervious streambed was represented as a vertical layer of lower-conducting material extending throughout the saturated thickness of the aquifer. The Hantush model was based on the principal of additional seepage resistance due to this semipervious layer. Seepage resistance extended the distance between the well and stream by an effective distance. Therefore, the streambed layer of lower hydraulic conductivity created a flow resistance equal to the ratio between the hydraulic conductivity of the aquifer, $K\left(\mathrm{~m} \mathrm{~d}^{-1}\right)$, and the streambed conductivity, $K_{s b}\left(\mathrm{~m} \mathrm{~d}^{-1}\right)$, divided by the streambed thickness, $M(\mathrm{~m})$. As noted by Sophocleous et al. (1995) and Conrad and Beljin (1996), the Theis (1941) and Hantush (1965) analytical models failed to adequately represent the physical conditions representative of alluvial aquifer systems.

Hunt (1999) developed an analytical model that incorporated streambed conductance and stream partial penetration in the simulation of a groundwater pumping well located near a stream, as shown in figure 1c. Hunt's (1999) model assumed a homogeneous, isotropic aquifer of infinite extent with Dupuit flow. The model also assumed that changes in stream water surface elevation due to pumping were small, and vertical and horizontal streambed crosssections were small compared to the aquifer saturated thickness. Seepage flow rates from the stream into the aquifer were assumed linearly proportional to the head gradient between the aquifer and stream, dependent upon the streambed conductance, $\lambda\left(\mathrm{m} \mathrm{d}^{-1}\right)$ :

$$
\lambda=\frac{K_{s b} W}{M}
$$

where $W$ is the width of the stream (m). The product of $\lambda$ and the head gradient between the aquifer and stream gave the
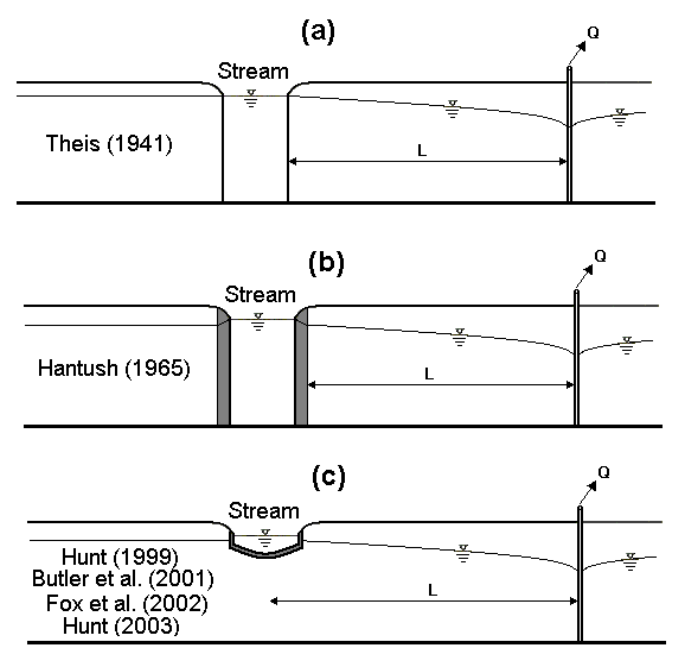

Figure 1. Hydrologic conditions modeled by numerous analytical solutions $Q$ is the constant discharge rate of the pumping well, and $L$ is the distance between the pumping well and stream). stream leakage per unit length of stream. Hunt derived both a streamflow depletion equation (eq. 4) and drawdown equation (eq. 5) applicable throughout the infinite domain:

$$
\begin{aligned}
& \frac{Q_{s}}{Q}=\operatorname{erfc}\left(\sqrt{\frac{S L^{2}}{4 T t}}\right)-\exp \left(\frac{\lambda^{2} t}{4 S T}+\frac{\lambda L}{2 T}\right) \\
& \cdot \operatorname{erfc}\left(\sqrt{\frac{\lambda^{2} t}{4 S T}}+\sqrt{\frac{S L^{2}}{4 T t}}\right) \\
& s_{w}(x, y, t)=\frac{Q}{4 \pi T}\left\{E_{1}\left[\frac{(L-x)^{2}+y^{2}}{4 T t / S}\right]\right. \\
& \left.-\int_{0}^{\infty} e^{-\theta} E_{1}\left[\frac{(L+|x|+2 T \theta / \lambda)^{2}+y^{2}}{4 T t / S}\right] d \theta\right\}
\end{aligned}
$$

where $Q_{s}$ is the stream depletion rate $\left(\mathrm{m}^{3} \mathrm{~d}^{-1}\right), E_{1}$ is the well function or exponential integral (Charbeneau, 2000), $S$ is the aquifer storage coefficient or specific yield, $t$ is the time since the start of pumping (d), and $x$ and $y$ are the locations within the infinite domain with respect to a datum at the stream on a perpendicular line with the well $(\mathrm{m})$. Additional solutions that expand in complexity have been proposed by Butler et al. (2001) for finite width streams in an aquifer of limited lateral extent, Fox et al. (2002) for finite-width, small streams, Hunt (2003) for semiconfined aquifers, and Chen and Yin (2004) for base flow reduction and stream infiltration.

The benefits of these analytical solutions are their simplicity compared to numerical models (e.g., Fox and Gordji, 2007) and that tests can be conducted to simultaneously estimate aquifer and reach-scale streambed parameters in what has been termed a stream-aquifer analysis (SAA) test (Hunt, 1999; Fox, 2004, 2007). The disadvantage of many of the recent solutions is that most are based on differential equations so mathematically complex that they require numerical inversion of Laplace transforms to derive a semi-analytical solution. In addition, numerous parameters and limited groundwater data make unique solutions difficult to obtain.

Predicted $K_{s b}$ from SAA tests has been hypothesized to better represent the spatially variable, reach-scale $K_{s b}$ as opposed to point, in situ measurements, which can vary significantly for different measurement techniques and across a stream cross-section (Landon et al., 2001; Fox, 2004). However, only a few SAA tests have been documented in the literature and compared to field-measured $K_{s b}$ or $\lambda$, e.g., Hunt et al. (2001) in New Zealand, Nyholm et al. (2002) in Denmark, and Fox (2004) in eastern Colorado. Field data from multiple regions are needed to assess the applicability and predictive capability of these analytical solutions. Therefore, the objective of this research was to perform a SAA test at a well site along the North Canadian River in central Oklahoma for the purpose of evaluating the ability of an analytical solution, when applied to the SAA test data, to estimate a reach-scale streambed conductance. 


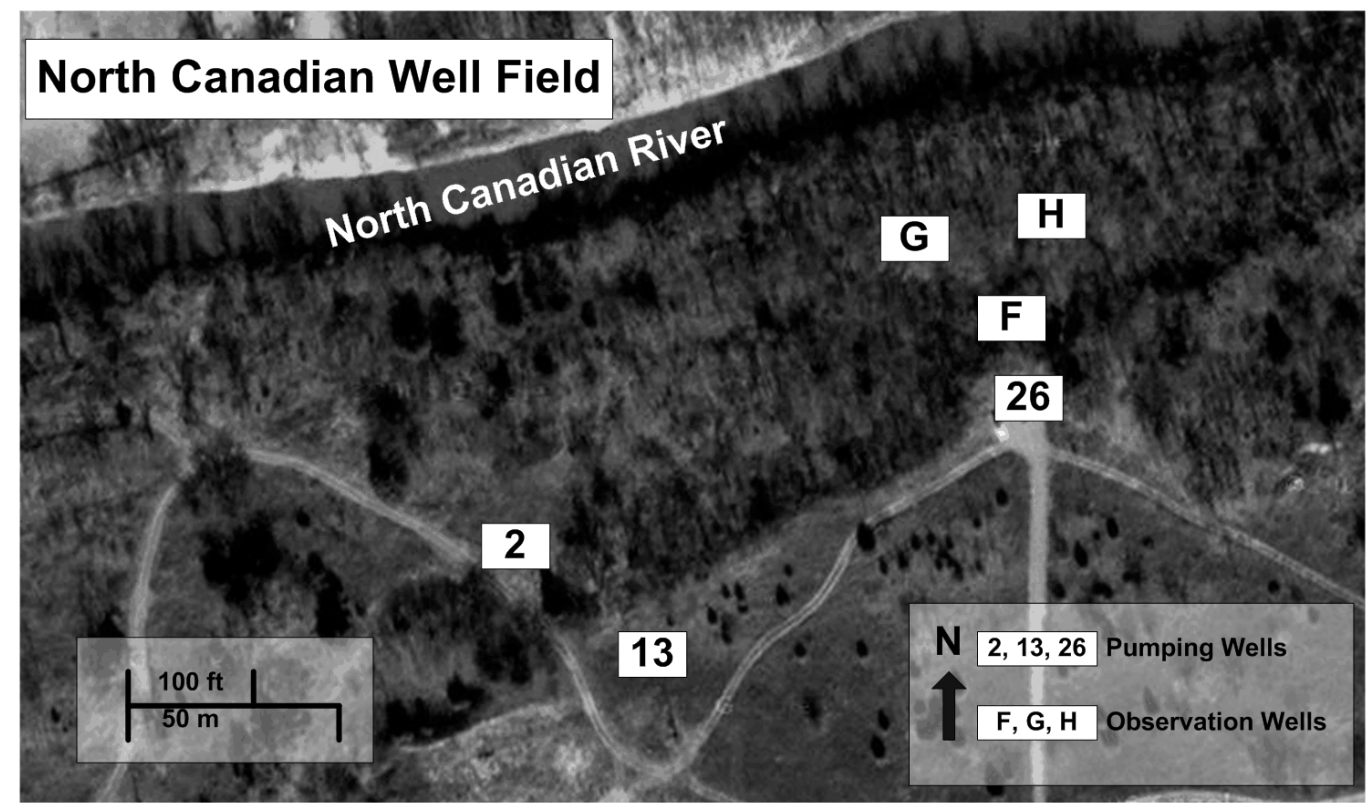

Figure 2. North Canadian River well field site. Observation wells were installed around two active pumping wells (2 and 26$)$. Pumping well 26 and observation wells $\mathbf{F}$, $G$, and $H$ were utilized for the stream-aquifer analysis test.

\section{Materials ANd Methods}

The field site was located just north of El Reno, Oklahoma, on the North Canadian River (fig. 2). The North Canadian River is a sand bed, partially penetrating (incised) stream that does not extend throughout the entire saturated thickness of the alluvial aquifer. The surface geology of the site is mostly composed of Quaternary alluvial sands and gravels with some interdispersed clay lenses. These deposits are both aeolian and fluvial in origin, usually no more than 15 to $20 \mathrm{~m}$ in thickness, and the width extends approximately $1.6 \mathrm{~km}$ from the North Canadian River. Driller's logs in the area have reported mostly fine sand with interdispersed clay (ACOG, 2009). Ryder (1996) reports specific yield $(S)$ and $K$ estimates of 0.29 and $48 \mathrm{~m} \mathrm{~d}^{-1}$, respectively.

Observation wells were installed to a depth of approximately $8 \mathrm{~m}$, constructed of Schedule $40 \mathrm{PVC}$, and had a $5 \mathrm{~m}$ screened section at the base. The observation wells were installed using a Geoprobe (Kejr, Inc., Salina, Kans.) drilling machine. Three observation wells were installed between pumping well 26 and the North Canadian River (fig. 2). Drawdown and temperature were measured every 5 min using automated water level loggers (HoboWare, Onset Computer Corp., Bourne, Mass.) installed in each observation well. One logger was also installed in the North Canadian River to monitor stream stage and temperature.

Two measurement techniques were used to estimate $K_{s b}$. First, streambed sediment samples were acquired from the upper 5 to $10 \mathrm{~cm}$ of the streambed at five locations along a $300 \mathrm{~m}$ reach of the North Canadian River near the observation well field (extent of the stream shown in fig. 2). Three of the points were in the thalweg of the stream and two points were in sand beds closer to the south bank. Sediment samples were sieved, and the soil texture was determined. The isotropic $K_{s b}$ was estimated based on the $d_{10}$ (the effective grain diameter, $\mathrm{mm}$ ) and $d_{50}$ (the median grain diameter, mm) using the Alyamani and Sen (1993) equation:

$$
K_{s b}=1300\left[I_{o}+0.025\left(d_{50}-d_{10}\right)\right]^{2}
$$

where $I_{o}$ is the intercept (mm) of the line formed by $d_{50}$ and $d_{10}$ with the grain-size axis. Second, vertical $K_{s b}$ was measured using falling-head permeameter tests at the same five locations (fig. 2). Permeameter tests were performed by pushing a pipe partially into the streambed $(10$ to $20 \mathrm{~cm})$ and adding water to induce a hydraulic gradient on the sediments inside the pipe. The water level inside the pipe was allowed to fall while the water level was measured over time. Vertical $K_{s b}$ was calculated using an application of Darcy's equation (Landon et al., 2001; Fox, 2004):

$$
K_{s b}=\frac{d}{\left(t-t_{0}\right)} \ln \left(\frac{H_{0}}{H(t)}\right)
$$

where $H(t)$ is the water level elevation above the stream level at various times during the experiment, $t_{0}$ is the initial time, $H_{0}$ is the initial water level elevation in the pipe above the stream water level, $d$ is the sediment interval being tested (10 to $20 \mathrm{~cm})$, and $\left(t-t_{0}\right)$ is the elapsed time. Each test was performed for at least $5 \mathrm{~min}$ with measurements of the head, $H(t)$, inside the pipe approximately every $30 \mathrm{~s}$. Equation 7 was rearranged and used to inversely estimate a single $K_{s b}$ from the $t$ versus $H(t)$ data by iterating on $K_{s b}$ until minimizing the sum of squared errors (SSE) between measured and predicted $H(t)$.

We had limited control over the operation of the pumping well field. For several months prior to and during the SAA test, pumping well 2 was pumped continuously; therefore, pumping well 26 was used for the SAA test with the assumption of a constant, approximately equivalent interference on the observation wells from other pumping wells. Pumping well 26, located approximately $85 \mathrm{~m}$ from the North Canadian River, discharged water at a constant rate of $2180 \mathrm{~m}^{3} \mathrm{~d}^{-1}$ for $90 \mathrm{~h}$ from 18 to 22 October 2009 after being off for approximately four days. Pumping well 26 was a typical well within the well field with an approximate 
Table 1. Coordinate locations of the pumping and observation wells utilized in the stream-aquifer analysis test along the North Canadian River. The origin of the coordinate system is at the stream on a perpendicular line with the well.

\begin{tabular}{cccc}
\hline $\begin{array}{c}\text { Well Identification } \\
\text { (fig. 2) }\end{array}$ & $\begin{array}{c}x \\
(\mathrm{~m})\end{array}$ & $\begin{array}{c}y \\
(\mathrm{~m})\end{array}$ & $\begin{array}{c}Q \\
\left(\mathrm{~m}^{3} \mathrm{~d}^{-1}\right)\end{array}$ \\
\hline 26 & 85 & 0 & 2180 \\
$\mathrm{~F}$ & 70 & 0 & -- \\
$\mathrm{G}$ & 41 & -15 & -- \\
$\mathrm{H}$ & 50 & 19 & -- \\
\hline
\end{tabular}

diameter of $65 \mathrm{~cm}$, a depth of $16 \mathrm{~m}$, and screened section (stainless steel) from 12 to $16 \mathrm{~m}$. The drawdown response due to groundwater extraction was measured in observation wells $\mathrm{F}, \mathrm{G}$ and $\mathrm{H}$, as shown in figure 2 . Spatial locations relative to a coordinate origin at the stream and on a perpendicular line with the well are provided in table 1.

Predicted $s_{w}$ using the Hunt (1999) solution was fit to the observed $s_{w}$ measured in observation wells $\mathrm{F}, \mathrm{G}$, and $\mathrm{H}$. The Hunt (1999) solution required estimates of $T, S$, and $\lambda$. Parameter estimates were derived by minimizing the difference between the predicted and observed drawdown. Initial estimates of the aquifer parameters were based on previously reported values for $T$ and $S$ (Ryder, 1996). The acceptability of the fit of the solutions to the observed data was evaluated by utilizing an acceptance criterion and a quantitative index, the normalized objective function (NOF) (Pennell et al., 1990; Hession et al., 1994). The NOF is the ratio of the standard deviation of differences (STDD) to the overall mean $\left(X_{a}\right)$ of the observed parameter:

$$
\mathrm{NOF}=\frac{\mathrm{STDD}}{X_{a}}=\frac{\sqrt{\frac{\sum_{i=1}^{n}\left(x_{i}-y_{i}\right)^{2}}{n}}}{X_{a}}
$$

where $x_{i}$ and $y_{i}$ are the $i$ th observed and predicted values, respectively, and $n$ is the number of observations. The NOF has been used in the past for model evaluation (Pennell et al., 1990; Hession et al., 1994; Fox et al., 2006). In general, 1\%, $10 \%$, and $50 \%$ deviations from the observed values result in NOF values of $0.01,0.10$, and 0.50 , respectively. Inverse estimation was deemed acceptable when NOF approached 0.02 , or $2 \%$ average deviation from the observed values.

For the Hunt (1999) solution, which utilized partial differential equations for confined flow as estimates for unconfined flow, the fit was confined to the late-time drawdown data (i.e., delayed yield effects were neglected). For drawdown in an unconfined aquifer, two sections of a $s_{w}$ curve can be distinguished: early time response associated with elastic storage and parameterized by the storage coefficient, and late time response parameterized by the specific yield. Confined flow equations can be used for this latter section if using a corrected $s_{w}$ to account for changes in the saturated thickness of the aquifer (Charbeneau, 2000). However, for the North Canadian River alluvial aquifer, the initial saturated thickness was 15 to $20 \mathrm{~m}$, and therefore the range of $s_{w}$ was generally small compared to the saturated thickness such that the correction was not significant (Charbeneau, 2000). Focusing on only the late-time response was deemed reasonable since the goal was to predict aquifer and streambed parameters for long-term water management.
Inversely estimated $T, S$, and $\lambda$ were compared to parameters estimated from previous studies and also the $\lambda$ derived from $K_{s b}$ (measured from falling-head permeameter tests), the measured $W$, and estimated $M$. Using the parameter estimates, stream depletion due to groundwater pumping during the SAA test was predicted to assess the importance of alluvial well depletion on streamflow.

\section{RESUlts AND Discussion}

All streambed sediment samples were classified as coarse sand. Approximately $99 \%$ of each of the five streambed samples was sediment with particle sizes greater than $0.075 \mathrm{~mm}$ (fig. 3). The Alyamani and Sen (1993) equation estimated $K_{s b}$ as approximately $30 \mathrm{~m} \mathrm{~d}^{-1}$ based on $d_{50}=$ $0.37 \mathrm{~mm}$ and $d_{10}=0.19 \mathrm{~mm}$. Streambed $K_{s b}$ estimates from the falling-head permeameters had low variability (i.e., coefficient of variation of 0.2 ) for this reach of the North Canadian River (fig. 4), especially compared to previous data reported in the literature (Landon et al., 2001; Fox, 2004). Only small differences were estimated in thalweg versus edge of channel (i.e., sand bar) measurements. The three thalweg permeameter tests estimated $K_{s b}$ in the range of 13.9 to $20.6 \mathrm{~m} \mathrm{~d}^{-1}$, with the $K_{s b}$ estimated for the sand bars within this range (i.e., 14.6 and $19.0 \mathrm{~m} \mathrm{~d}^{-1}$ ). These $K_{s b}$ measurements were on the same order of magnitude of $K$ for the aquifer material, suggesting minimal hydraulic restriction at the streambed. With such high $K_{s b}$, it was difficult to identify any streambed restriction layer and therefore challengingto estimate the streambed thickness $(M)$. The width $(W)$ of the North Canadian River was typically between 20 and $25 \mathrm{~m}$. Based on equation 3 , the estimated $\lambda$ was on the order of 1000 $\mathrm{m} \mathrm{d}^{-1}$.

Long-term monitoring data indicated some interesting trends in the water level response between the stream and observation wells. For example, a rise in stream stage starting on approximately 9 October resulted in a corresponding increase in water levels in observation wells $F, G$, and $\mathrm{H}$ (fig. 5). The variability in water levels from 3 to 8 October was most likely due to changes in the pumping rate of pumping well 26, with $\mathrm{G}$ and $\mathrm{H}$ having an almost equivalent water level response.

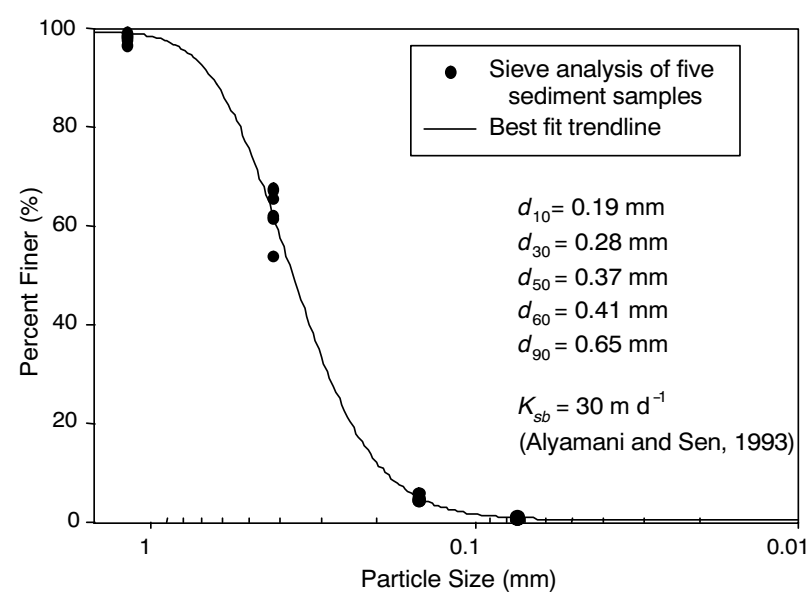

Figure 3. Grain-size distribution measured from five streambed sediment samples in the North Canadian River. The best-fit trend line was used to derive the representative grain size diameters $\left(d_{10}, d_{30}, d_{50}, d_{60}\right.$, and $\left.d_{90}\right)$. 
(a) Thalweg Permeameter Tests

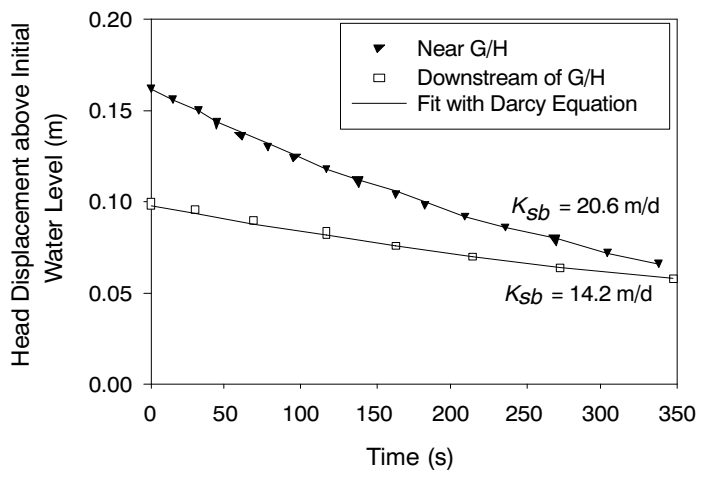

(b) Streambed Conductivity Estimates

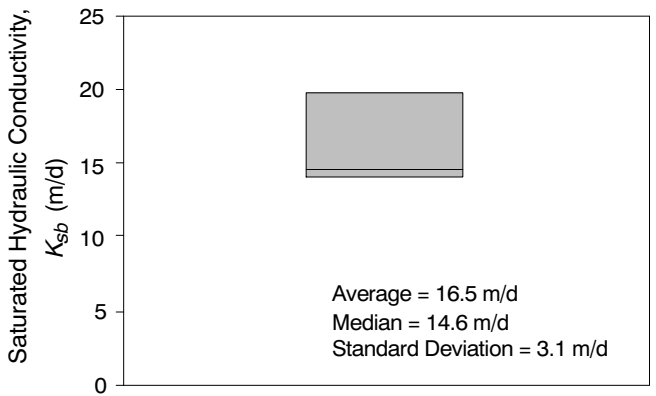

Figure 4. (a) Example data from two streambed hydraulic conductivity $\left(K_{s b}\right)$ measurements using falling-head permeameter tests including the resulting fit of the data with the Darcy equation, and (b) box plot resulting from five $K_{s b}$ measurements for both thalweg and sand bars in the North Canadian River.

For the SAA test period, the initial gradient was directed from the stream and into the alluvial aquifer (i.e., a stream depletion condition), as shown in figure 5. The initial hydraulic gradient was $0.017 \mathrm{~m} \mathrm{~m}^{-1}$ based on a transect from the stream through observation wells $G$ and F. Most analytical solutions assume an initial water table equivalent to the stream water level; therefore, the initial hydraulic gradient experienced during the project period was a slight deviation from the model assumptions. This and other deviations from the assumptions of the analytical solution could increase the variability of inversely estimated aquifer and stream parameters from the observation wells.

The Hunt (1999) solution was fit to the late-time drawdown data, thereby neglecting delayed yield effects (fig. 6). Late-time $s_{w}$ data were considered to be data collected at greater than 1000 min from the initiation of pumping based on an appropriate fit of the Hunt (1999) solution to the observed data within ranges of $T$ and $S$ that were similar to previous investigations in the groundwater system. Inversely estimated $T$ and $S$ ranged from 790 to $950 \mathrm{~m}^{2} \mathrm{~d}^{-1}$ and from 0.19 to 0.28 , respectively (fig. 6). Also note that $\lambda$ estimated from the SAA test was similar to the values estimated from the falling-head permeameter tests, providing further evidence and support for the use of SAA tests for deriving reach-scale $\lambda$. While it would have been ideal for the groundwater pumping to continue until reaching

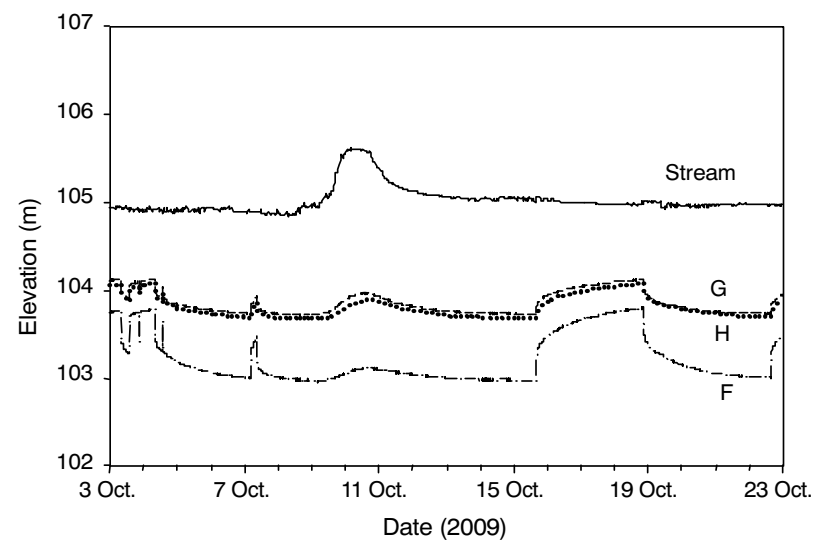

Figure 5. Water levels in the North Canadian River and observation wells during October 2009. The stream-aquifer analysis test was performed from 18 to 22 October. steady-state drawdown in the observation wells, we had limited control on the operation of the well field and therefore were limited to the available data. Descriptive statistics of the fit between observed and predicted late-time (i.e., $t$ greater than $1000 \mathrm{~min}$ ) drawdown data are shown in table 2. The NOF values for all three observation wells were less than 0.02 .

Equivalent to the in-stream measurements, estimates for $\lambda$ from the SAA test suggested that this reach of the North Canadian River was equivalent to a fully penetrating stream with no streambed resistance. Drawdown from observation well $F$ suggested that $\lambda$ equal to and greater than $600 \mathrm{~m} \mathrm{~d}^{-1}$ was reasonable. As $\lambda$ increased in the Hunt (1999) solution, equation 5 converged to the Theis (1941) solution for a fully penetrating stream with no streambed resistance (fig. 1a). In fact, predictions by the Theis (1941) solution with image wells using the inversely estimated $T$ and $S$ closely matched the predictions by the Hunt (1999) solution with $\lambda$ equal to or greater than $600 \mathrm{~m} \mathrm{~d}^{-1}$, as shown in figure $6 \mathrm{a}$. Also included in this figure is the predicted drawdown response due to pumping without considering induced recharge from the stream, i.e., the Theis (1935) solution. It is apparent from this figure that the stream provided a recharge source for the pumping well. Estimates of $\lambda$ when using observations wells $\mathrm{G}$ and $\mathrm{H}$, located closer to the stream, were equal to and greater than $1500 \mathrm{~m} \mathrm{~d}^{-1}$. These observation wells provided data at locations closer to the stream where the interaction of the stream and aquifer was more pronounced. This is one reason why Fox (2007) emphasized the use of multiple observation wells, including wells closer to the stream, when performing SAA tests.

Note that variability was observed in the aquifer parameters estimated when using the three observation wells, even for a case with minimum streambed restriction. This

Table 2. Descriptive statistics of the fit between predicted and observed drawdown (late-time data) when using the Hunt (1999) solution (SSE = sum of squared errors, $n=$ number of data points, STDD $=$ standard deviation of differences, $X_{a}=$ average observed drawdown, and NOF = normalized objective function).

\begin{tabular}{cccccc}
\hline $\begin{array}{c}\text { Well Identification } \\
\text { (fig. 2) }\end{array}$ & SSE & $n$ & STDD & $X_{a}$ & NOF \\
\hline F & 0.09 & 891 & 0.01 & 0.73 & 0.01 \\
G & 0.07 & 891 & 0.01 & 0.35 & 0.02 \\
H & 0.07 & 891 & 0.01 & 0.34 & 0.02 \\
\hline
\end{tabular}


(a) Observation Well F

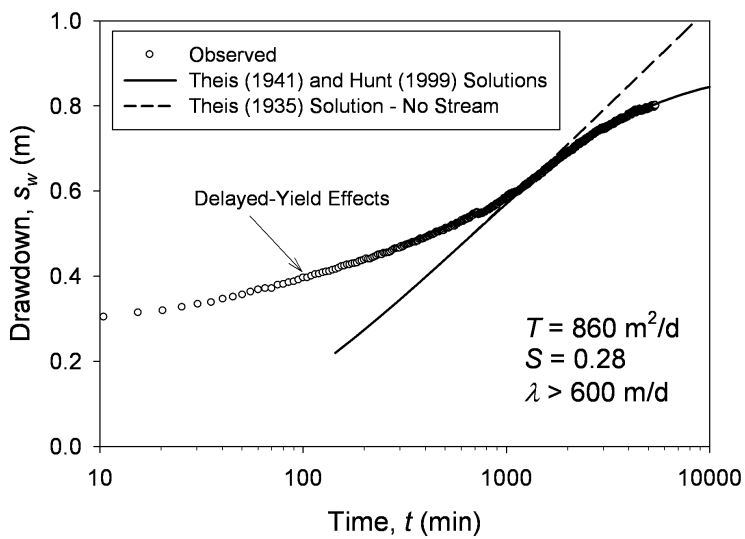

(b) Observation Well G

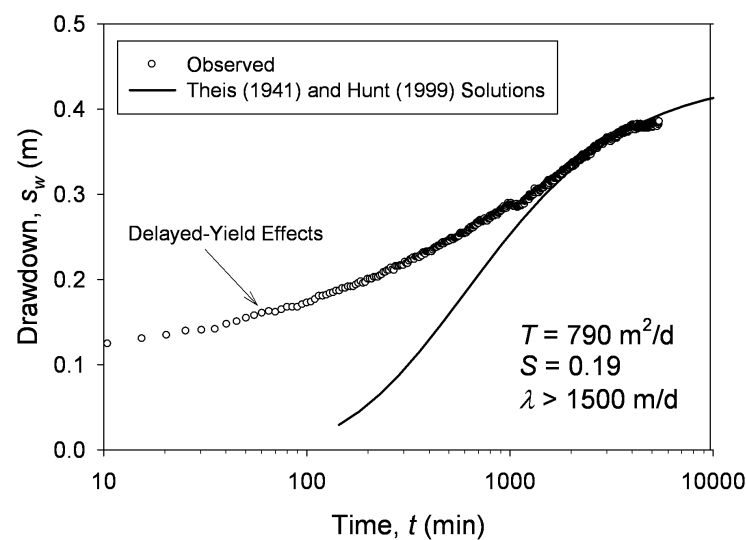

(c) Observation Well H

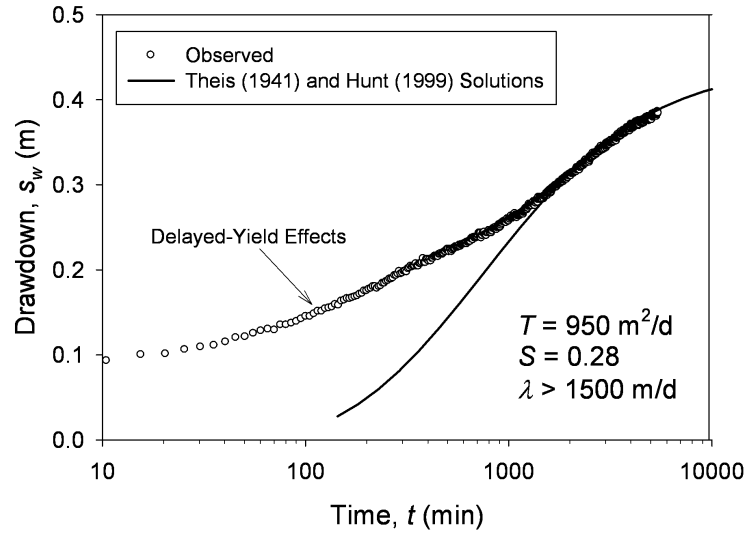

Figure 6. Inversely estimated aquifer transmissivity $(T)$, specific yield $(S)$, and streambed conductance $(\lambda)$ derived from fitting the Hunt $(1999)$ analytical solution to the observed drawdown during the stream-aquifer analysis test.

variability was due to (1) heterogeneity of the aquifer material, as discussed by Ryder (1996), and (2) imperfect characterization of the system due to inadequate assumptions, such as the initial water level gradient prior to the stream-aquifer analysis test and the partial penetration of the pumping well. Such limitations should be realized when evaluating the accuracy and precision of inversely estimated aquifer and streambed parameters. However, slight variation away from model assumptions is inherent in most applications of an analytical solution to real-world problems.

Estimated stream depletion based on the Hunt (1999) solution, i.e., equation 4, using the inversely estimated parameters from observation wells $\mathrm{F}, \mathrm{G}$, and $\mathrm{H}$ were as high as $30 \%$ to $35 \%$ of $Q$ after one day of pumping and approached $60 \%$ to $70 \%$ of $Q$ approximately five days after initiation of pumping (fig. 7). Since $\lambda$ was relatively large, equation 4 simplified to the following:

$$
\frac{Q_{s}}{Q}=\operatorname{erfc}\left(\sqrt{\frac{S L^{2}}{4 T t}}\right)
$$

For the North Canadian River, it is suggested that this equation should be used as a first estimate of stream depletion unless reach conditions (i.e., measurements of $\lambda$ ) suggest otherwise. Then, the full depletion solution, i.e., equation 4 , should be used.

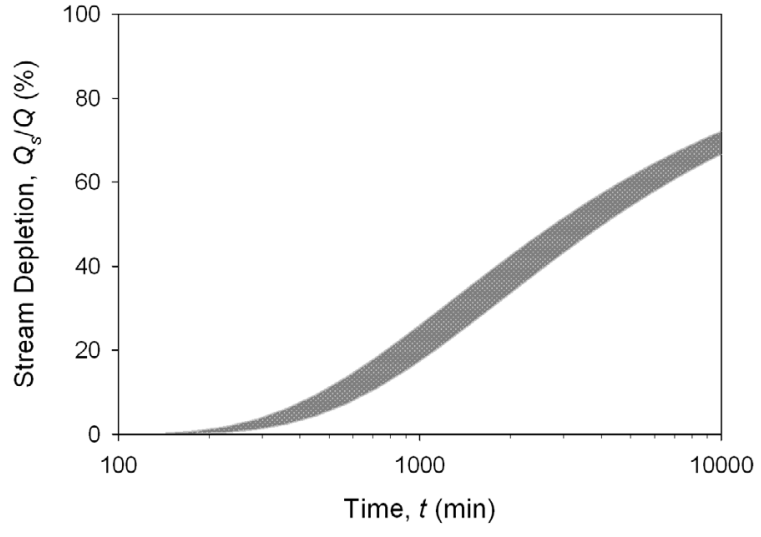

Figure 7. Estimated stream depletion $\left(Q_{s} / Q\right.$, where $Q$ is the groundwater pumping rate) due to pumping well 26 during the stream-aquifer analysis test. The range in estimated stream depletion was derived using the Hunt (1999) solution with inversely estimated aquifer and streambed parameters from observation wells $F$, G, and $H$.

\section{Summary and Conclusions}

The stream-aquifer analysis test conducted on the North Canadian River provided field data that supported the use and applicability of simpler drawdown and stream depletion analytical solutions. Support for the simpler solutions was largely based on the fact that the North Canadian River behaved similar to a fully penetrating stream with little to no 
hydraulic resistance provided by a streambed layer. Even though the stream only partially penetrated into the alluvial aquifer, the lack of hydraulic resistance resulted in drawdown profiles that suggested the alluvial aquifer intensely interacted with the stream. In fact, estimated stream depletion was as high as $60 \%$ to $70 \%$ of the groundwater pumping rate after only five days of pumping. In-stream streambed hydraulic conductivity estimates from fallinghead permeameter tests were on the order of $20 \mathrm{~m} \mathrm{~d}^{-1}$ and had low variability (i.e., coefficient of variation of 0.2 ), especially compared to the high variability in field-measured streambed hydraulic conductivity reported in previous studies. The similarity in streambed conductance estimates from in-stream measurements and the stream-aquifer analysis test further supported the use of such tests to estimate reach-scale streambed conductance. It should be noted that inversely estimated parameters from the observed drawdown were based on only late-time drawdown data, thereby neglecting delayed yield effects of the unconfined aquifer. This was reasonable because of the interest in long-term (i.e., multiple days to months) pumping effects and the small drawdown compared to the original saturated thickness of the aquifer. With this realization, more complex solutions were not warranted for this system, which considerably simplified the mathematical complexity of the analytical solutions to be used and the number of parameters required to be estimated to parameterize the stream-aquifer interaction.

\section{ACKNOWLEDGEMENTS}

This material is based upon work supported by a FY 2009 Oklahoma Water Resources Research Institute (OWRRI) and Oklahoma Water Resources Board (OWRB) grant under the U.S. Geological Survey 104b program. We acknowledge the city of El Reno, Mr. Jim Luckett Jr. and Mr. Darrel White for providing access to the site. We also acknowledge Amanda K. Fox, Stillwater, Oklahoma, for reviewing an earlier version of the manuscript.

\section{REFERENCES}

ACOG. 2009. Resistivity survey 2009: El Reno well field. Oklahoma City, Okla.: Association of Central Oklahoma Governments, Water Resources Division.

Alyamani, M. S., and Z. Sen. 1993. Determination of hydraulic conductivity from grain-size distribution curves. Ground Water 31(4): 551-555.

Butler, J. J., V. A. Zlotnik, and M. S. Tsou. 2001. Drawdown and stream depletion produced by pumping in the vicinity of a partially penetrating stream. Ground Water 39(5): 651-659.

Charbeneau, R. J. 2000. Groundwater Hydraulics and Pollutant Transport. Upper Saddle River, N.J.: Prentice Hall.

Chen, X., and Y. Yin. 2004. Semianalytical solutions for stream depletion in partially penetrating streams. Ground Water 42(1): 92-96.
Conrad, L. P., and M. S. Beljin. 1996. Evaluation of an induced infiltration model as applied to glacial aquifer systems. $J$. American Water Resour. Assoc. 32(6): 1209-1220.

Fox, G. A. 2004. Evaluating stream depletion analytical solutions using field data from a stream/aquifer analysis test. J. American Water Resour. Assoc. 40(3): 755-763.

Fox, G. A. 2007. Estimating streambed conductivity: Guidelines for stream-aquifer analysis tests. Trans. ASABE 50(1): 107-113.

Fox, G. A., and L. Gordji. 2007. Consideration for unsaturated flow beneath a streambed during alluvial well depletion. J. Hydrol. Eng. ASCE 12(2): 139-145.

Fox, G. A., P. DuChateau, and D. S. Durnford. 2002. Analytical model for aquifer response incorporating distributed pumping-induced stream leakage. Ground Water 40(4): 378-384.

Fox, G. A., G. J. Sabbagh, W. Chen, and M. Russell. 2006. Comparison of uncalibrated Tier II ground water screening models based on conservative tracer and pesticide leaching. Pest Mgmt. Sci. 62(6): 537-550.

Hantush, M. S. 1965. Wells near streams with semipervious beds. $J$. Geophys. Res. 70(12): 2829-2838.

Hession, W. C., V. O. Shanholtz, S. Mostaghimi, and T. A. Dillaha. 1994. Uncalibrated performance of the finite element storm hydrograph model. Trans. ASAE 37(3): 777-783.

Hunt, B. 1999. Unsteady stream depletion from ground water pumping. Ground Water 37(1): 98-102.

Hunt, B. 2003. Unsteady stream depletion when pumping from semiconfined aquifer. J. Hydraul. Eng. ASCE 8(1): 12-19.

Hunt, B., J. Weir, and B. Clausen. 2001. A stream depletion field experiment. Ground Water 39(2): 283-289.

Jenkins, C. T. 1968. Techniques for computing rate and volume of stream depletion by wells. Ground Water 6(2): 37-46.

Landon, M. K., D. L. Rus, and F. E. Harvey. 2001. Comparison of instream methods for measuring hydraulic conductivity in sandy streambeds. Ground Water 39(6): 870-885.

Nyholm, T., S. Christensen, and K. R. Rasmussen. 2002. Flow depletion in a small stream caused by ground water abstraction from wells. Ground Water 40(4): 425-437.

Pennell, K. D., A. G. Hornsby, R. E. Jessup, and P. S. C. Rao. 1990. Evaluation of five simulation models for predicting aldicarb and bromide behavior under field conditions. Water Resour. Res. 26(11): 2679-2693.

Ryder, P. D. 1996. Ground water atlas of the United States: Oklahoma, Texas: HA 730-E. Washington, D.C.: USGS. Available at: http://pubs.usgs.gov/ha/ha730/ch_e/ E-alluvial_aquifers.html.

Sophocleous, M., A. Koussis, J. L. Martin, and S. P. Perkins. 1995. Evaluation of simplified stream-aquifer depletion models for water rights administration. Ground Water 33(4): 579-588.

Spalding, C. P., and R. Khaleel. 1991. An evaluation of analytical solutions to estimate drawdowns and stream depletions by wells. Water Resour. Res. 27(4): 597-609.

Theis, C. V. 1935. The relation between the lowering of the piezometric surface and the rate and duration of discharge of a well using groundwater storage. American Geophys. Union Trans. 16: 519-524.

Theis, C. V. 1941. The effect of a well on the flow of a nearby stream. American Geophys. Union Trans. 22(3): 734-738. 
